\title{
THE EFFECT OF EXPERIENCED HIGH-PERFORMANCE WORK SYSTEM AND PERCEIVED ORGANIZATIONAL SUPPORT ON PERCEIVED WORKLOAD THROUGH PSYCHOLOGICAL EMPOWERMENT AND JOB DEMANDS
}

\author{
Heldy Theresia Simanjuntak* \\ University of Indonesia, Indonesia
}

\begin{abstract}
Discussion of the integrative model of high-performance work systems experienced by employees (experienced HPWS) and the perceived organizational support simultaneously test for positive and negative effects on perceived workload (PW). A recent study shows the situation that occurs in the company where employees feel burdened by the workload they have and do not get additional compensation for the excess work they do. As a company, Bayer Indonesia regularly conducts surveys to assess several aspects, including employee engagement. Based on the 2020's employee survey result, employees perceive their current workload to be relatively high, which is evaluates as a result of processes, policies, and systems that occur in the company. This research is using Job Demands (JD) and Psychological Empowerment (PE) as a mediating. This research is an empirical study using quantitative data using a one-time data collection from survey to 200 employees. Data analysis using Structural Equation Model (SEM) -AMOS 22 software. The research has expected to provide insights to the respective company to evaluate existing policies and consider making programs that improve engagement and performance. In addition to these objectives, this study's results can add references for other researchers who want to do similar research or its modifications.
\end{abstract}

Keywords: high-performance work systems; perceived organizational support; perceived workload; psychological empowerment, job demands

Experienced High

Performance Work

System and Perceived

Organizational

Support on Perceived

Workload Through

Psychological

Empowerment and

Job Demands 
A quarter of all employees view their jobs as the number one stressor in their lives, according to the Centers for Disease Control and Prevention. The World Health Organization describes stress as the "global health epidemic of the 21st century." Many of us now work in constantly connected, always-on, highly demanding work cultures where stress and the risk of burnout are widespread. Since the pace and intensity of contemporary work culture are not likely to change, it's more important than ever to build resilience skills to effectively navigate your work life (HBR, 2016). In a study conducted by IBM Institute for Business Value in late 2015, a survey of 5,247 business executives from 21 industries in over 70 countries reported that the "scope, scale and speed" of their businesses were increasing at an accelerated rate, especially as the competitive landscape becomes increasingly disrupted by technology and radically different business models. The result is at times a frenetic way of working. Being hyperconnected and responsive to work anytime, anywhere, can be extremely taxing. In a 2014 global survey of Human Capital Trends conducted by Deloitte, $57 \%$ of respondents said that their organizations are "weak" when it comes to helping leaders manage difficult schedules and helping employees manage information flow, and that there is an urgent need to address this challenge (HBR, 2016).

Stress and burnout related to the increasing pace and intensity of work are on the rise globally. A survey of over 100,000 employees across Asia, Europe, Africa, North America, and South America found that employee depression, stress and anxiety accounted for $82.6 \%$ of all emotional health cases in Employee Assistance Programs in 2014, up from 55.2\% in 2012. Also, a recent large-scale, longitudinal survey of over 1.5 million employees in 4,500 companies across 185 countries conducted as part of the Global Corporate Challenge found that approximately $75 \%$ of the workforce experienced moderate to high stress levels - and more specifically, that $36 \%$ of employees reported feeling highly or extremely stressed at work, with a further $39 \%$ reporting moderate levels of workplace stress (HBR, 2016). The current and rising levels of stress in the workplace should be cause for concern, as there is a direct and adverse relationship between negative stress, wellness and productivity. According to Mercer (2020), across job functions and countries in Asia, high work demands have emerged as the top driver of stress in the workplace. Nine in 10 indicated that their jobs required high mental focus and multitasking, while six in 10 reported a lack of control over the pace and order of work that they need to complete. Only $41 \%$ reported being able to take breaks when necessary. These are among initial findings of the Healthy Minds at Work Assessment conducted by Mercer between July and September in 2020 to help companies assess and address mental well-being in the workplace. The survey is the first of its kind in Asia to provide businesses with insights into their progress against four key workplace dimensions - "Leadership and Management Support"; "Culture and Social Interactions"; "Work Demands and Career Development"; and "Well-being" - of mental health risks.

The Asia-wide survey, which involved 2500 employees across nine industries (Aerospace, Consumer Goods, Chemicals, Finance, Healthcare, Logistics \& Supply Chain, Consulting and Industrial Automation), also found that strenuous work demands have resulted in poor work-life balance. For $83 \%$ of employees, working overtime more than three times a week is common. Over 70\% report working on rest days or beyond regular work hours. The impact is greater for those in more senior positions (Mercer, 2020). The survey also found that more employees in Asia are reporting high stress levels since the start of the pandemic. While only a handful of employees $(7 \%)$ reported a high level of pressure before the onset of the pandemic, the percentage has now tripled. The percentage of senior management and sales professionals who reported experiencing high levels of stress jumped from $9 \%$ to $33 \%$ and $37 \%$ respectively. Respondents who are divorced saw similar hikes in stress levels from $7 \%$ to $39 \%$ (Mercer, 2020). Despite elevated stress levels, employees across the board reflect that they feel well-supported by their managers and teams. Six in 10 shared that they always receive clear communication (67\%) and support from their managers. Support includes assistance to solve problems $(66 \%)$ or pointing them to others who can help (61\%). Respondents also appreciate being heard; with $61 \%$ sharing that their individual opinions and views are always taken into account..

According to Morgan McKinley (2019), based on survey to 1,500 individuals, who perform a range of different roles across Financial Services, Professional Services and Commerce industries in the UK, asking about their normal working weeks to investigate exactly what the different levels of working hours are and what the availability of flexibility is like for employees. the greatest proportion of respondents from each sector selected 38-42 hours. The industry with the highest percentage of employees working 43+ hours every week was Banking at $14 \%$, followed by Professional Services (11\%) and then Commerce \& Industry (9\%). In terms of how many extra hours are worked per week, Banking employees were the hardest pressed out of the three sectors, with a significant $20 \%$ working 10 or more extra hours every week, closely followed by Professional Services at $18 \%$ but are their employers even aware? It seems not: regardless of industry, employees work extra hours without recognition. $92 \%$ from the Banking sector, $89 \%$ from Professional Services and $90 \%$ of Commerce employees who work overtime receive no form of compensation. One of the commerce is Bayer Indonesia who currently employs 215 permanent employees in the Crop Science division. 
The company's success is driven by the engagement of its people and leader playing a critical to foster individual development and enhance the engagement of your team. There are several tools to assess employee's voices, such as using check-ins as a dialogue between responsible manager with team member with employee. The company also has 360 degrees feedback mechanism, leadership pulse survey, and employee survey than conducted Sys periodically. This study derived from the recent employee survey results (2020) show that there are four problems that employees perceive as daily and most important to them. The four variables are employee engagement, S leadership and philosophy, perceived workload, and daily job \& operating model.

The survey results show that of the four variables, then in fact, all four variables are problematic for employees. However, of the four variables, the most problematic is the variable (perceived) workload. In this variable, most employees do not agree that the workload so far is a natural thing and a necessity. Most of the employees tend to feel that the workload is too heavy. Based on the survey results, it means that the main problem felt by PT Bayer Indonesia's employees is the workload that is too heavy without any additional compensations. That is why there are some employees who are preparing to move to another company if the opportunity arises. Using the survey result, Bayer Indonesia is reflecting and recreating the solution that motivated their employees.

\section{LITERATURE STUDY}

Perceived workload is a job stressor or demand which consume individuals' energy in terms of psychological resources and time. Such demands acquire individuals' addition resources (time) (Sadiq, 2020). Workload is a workload associated with information processing tasks, but human activities include mental processing (Mansour \& Tremblay, 2016)

High-performance work system (HPWS) or high-performance systems are a series of human resource management (HRM) activities that are designed to encourage skills, motivation and engagement of employees to enable businesses to gain a sustainable competitive advantage (Tang et al., 2017). HPWS is described by Abubakar et al (2019) as a framework of human resources practices related to the attraction, selection, management, and retention of top human resources (Abubakar et al., 2019). HPWS can be measured into eight dimensions, namely selective staffing, comprehensive preparation, internal mobility, jobs stability, work description, result-oriented assessment, incentive incentives, and participation practice (García-Chas et al., 2014)

Perceived organizational support is addresses socio-emotional needs, contributes to greater organizational identification and engagement, an increased willingness to support the organization, and good psychological wellbeing (Kurtessis et al., 2017).

Psychological empowerment (PE) is a concept associated with positive psychology. Being motivational in orientation, PE is the feeling of being in control over the situations at work (Abbasi et al., 2020).

Job demands refer to those 'physical, psycho- logical, social, or organizational aspects of the job that require sustained physical and/or psychological effort and are therefore associated with certain physiological and/or psychological costs' (e.g., highwork pressure and exhaustion) (Kloutsiniotis \& Mihail, 2020).

The preparation of the research model began with the discovery of human resource problems at PT Bayer Indonesia, namely the occurrence of excessive workloads (perceived workload). The problems faced by PT Bayer Indonesia, perceived workload, theoretically means the dependent variable. Furthermore, a solution is sought for the dependent variable (perceived workload) which means looking for the independent variable and the mediating variable.

Based on the search results, it was found that empirical research conducted by (Liu et al., 2020), which positions perceived workload as the dependent variable, then experienced HPWS as an independent variable, as well as two mediating variables (perceived organizational support, and psychological empowerment). Liu et al (2019) 's empirical research model is the main reference in this study. Furthermore, in order for this research to have a difference and novelty (research novelty) with the empirical research model of Liu, Chow, Zhu \& Chen (2019), one more mediating variable is sought which can be influenced by the dependent variable experienced HPWS and at the same time the mediating variable affects the dependent variable perceived workload. The variables found were job demands used in (Kloutsiniotis \& Mihail, 2020) research model. Figure 6 presents the position of the variable job demands in Kloutsiniotis \& Mihail's (2019) empirical study (colored in red) affecting work overload.

After finding the variable job demands, a research model that combines the results of Liu et al (2019) and Kloutsinotis \& Mihail (2019) is created. The contribution of Lie et al (2019) is four variables, consisting of one independent variable (experienced HPWS), one dependent variable (perceived workload), and two mediating variables (perceived organizational support, and psychological), which are all used in this study. The contribution of Kloutsinotis \& Mihail (2019) is a mediating variable (job demands). The combined contributions of Lie et al (2019) and Kloutsinotis \& Mihail (2019) form a suitable model proposed in this study. The model uses five variables, consisting of one dependent variable (perceived workload), two independent variable (experienced HPWS) and perceived organizational support (POS) and two mediating variables psychological empowerment, and job demands. 


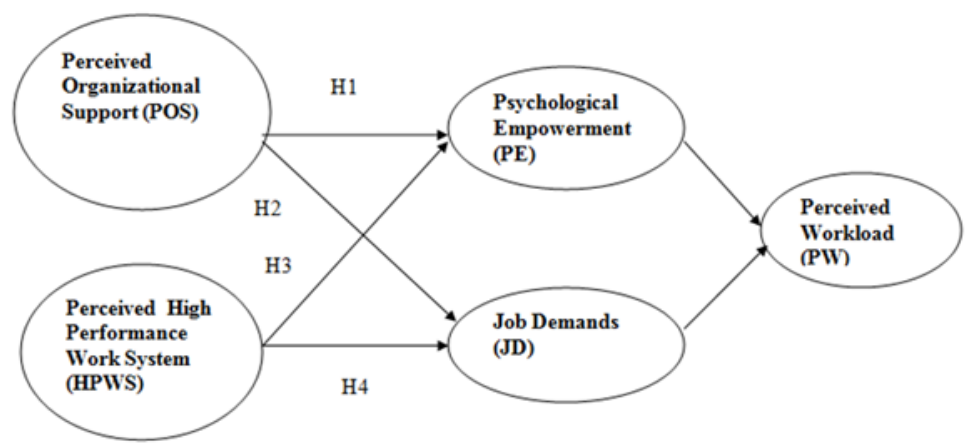

In accordance with the formulation of the problem, research objectives, theoretical studies, and previous research, 4 hypotheses were formulated:

The findings of Allen, Armstrong, Reid \& Riemenschneider (2008) empirical research show that 23 agencies and found increased workload resulted in dissatisfaction and demotivation. The result was not significant, therefore the expected high perceived workload to have a strongly negative relationship with POS was supported.

Based on the results of this study, the first hypothesis is compiled as follows:

Hypothesis 1: There will be a negative relationship between perceived organizational support (POS) and perceived workload (PW) is mediated by psychological empowerment (PE).

According to (Ghislieri et al., 2017), work demands were possible predictors of WFC, consistent with previous research (O'Driscoll et al. 2006, van Veldhoven \& Beijer 2012). Emotional dissonance was significant in work-to-family interactions: the effort required to display emotions at work different from those felt could have spillover effects in other life domains, supporting findings from other careers (Emanuel et al. 2014). WFC was negatively correlated with POS (cf. Gurbuz et al. 2012).

Based on the results of this study, a second hypothesis is compiled as follows:

Hypothesis 2: The relationship between perceived organizational support (POS) and perceived workload (PW) are positively related is mediated by job demand (JD).

The findings of (Mat et al., 2021) empirical research show that a predicted that perceived - HPWS and service employees' performance in the automotive retail industry is mediated by psychological empowerment. The research takes 4 steps to analyze the mediating effect. Firstly, perceived HPWS (independent variable) have to directly affect service employee performance (dependent variable). Next, to test the perceived HPWS have to directly influence the psychological empowerment (proposed mediator) and the proposed mediator has to directly influence the dependent variable. Finally, comparison of the significant values when the variables are added to the regression analysis. The results will be fully mediated when the significant relationship between independent variables and dependent variables must become insignificant after incorporating the mediator into the regression analysis. Based on the results of this study, the third hypothesis is compiled as follows:

Hypothesis 3: The relationship between perceived - HPWS (HPWS) and perceived workload (PW) is mediated by psychological empowerment (PE).

The results of empirical research by (Kloutsiniotis \& Mihail, 2020) proposed that employees' perceptions of HPWS will be positively associated with job demands (work overload and worked family conflict) and job resources, respectively. The findings showed that the relationship between HPWS and both job demands was negative and significant. Based on the results of this study, a fourth hypothesis is compiled as follows:

Hypothesis 4: The relationship between perceived - HPWS (HPWS) and perceived workload (PW) is negative mediated by job demand (JD).

\section{RESEARCH METHODOLOGY}

The unit of analysis in this study is the individual level of PT Bayer Indonesia employees. Population refers to a group of required information, whether a group of people, events, or interesting things being investigated by researchers (Sekaran \& Boeugie, 2016). The population includes the general population (general population), target population (target population), and accessible population (accessible population) (Asiamah et al., 2017). In this study, the general population (general population) are all permanent employees of PT Bayer Indonesia division Crop Science Division around 200 employees.

Meanwhile, the sample is part of the population that can be used to generalize the population (Tabachnick, BG, \& Fidell, 2013). However, considering that this research uses SEM AMOS 22 software, it means that it is included covariance-based (CB) SEM which is more compatible with a large sample size (Hair, JF, Hult, GTM, Ringle, CM, \& Sarstedt, 2014), so the entire target population in this study is used as the research sample. Sugiyono, 2013). The reason for using SEM is because the SEM method is a continuation of the multiple regression method and path analysis. all of which are multivariate analysis formats. 
Compared to the regression and path analysis methods, the SEM method is superior, because the SEM method can analyze data more comprehensively. In multiple regression analysis and path analysis, the analysis can only be carried out at the level of the latent variable (unobserved variable), while the SEM method can analyze at a more detailed level, namely the level of dimensions and indicators. SEM combines structural model testing System and Perceived and measurement models (the relationship between indicators and constructs), so that through SEM researchers can test measurement errors, and perform factor analysis along with hypothesis testing. Another advantage of SEM Su is that it is able to analyze the reciprocal relationship model (recursive) simultaneously, where this model cannot be solved by linear regression analysis simultaneously. Through SEM, bootstrapping can be done, an assumption facility for an increase in the number of samples, which linear regression analysis cannot do (Haryono, 2017: 9).

\section{RESULT AND DISCUSSION}

\section{Testing the measurement model (CFA)}

The Critical Ratio (CR) values from most measure was greater than the preferred $>1.96$ requirements of acceptability it is indicating a high level of internal consistency. There is relationship with $\mathrm{CR}<1.96$, Latent JD to PW, 1.751, Latent POS to PW -1.476, and Latent HPWS to PW -1.139. There are some measures with CR Value $>$ two digits, the highest is Latent POS to POS Indicator 11,565 and minimum CR value is relationship of Latent PE to PW -1.958.

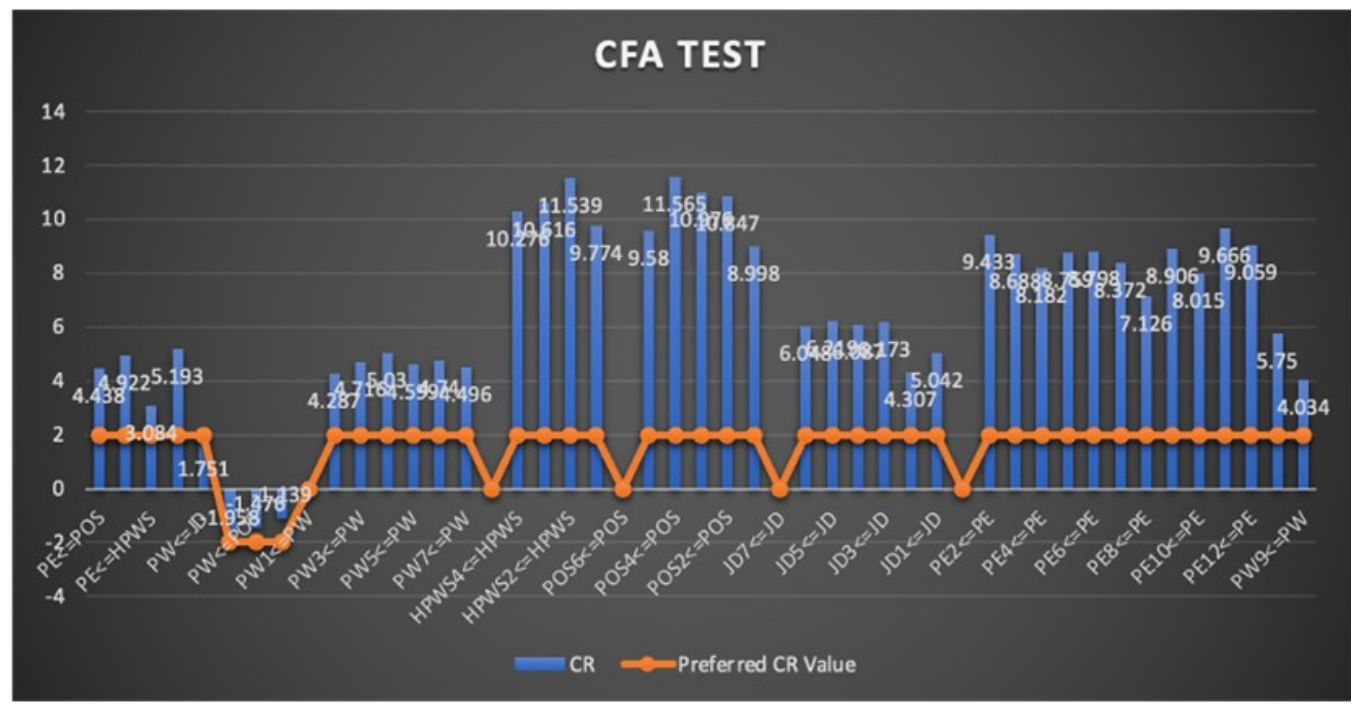

Organizational

upport on Perceived Workload Through Psychological

Empowerment and Job Demands

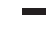

\section{Job Demands}

$+$ 
Variable is said to have good validity to something latent construct if: (i) factor loading is greater than the critical $t$ score $\geq 1.96$ or practically $\geq 2$. This value is seen at the AMOS output "Variances (Group Number 1Default model)". (ii) Standardized loading factors $\geq 0.7$.

Estimate values of all relationship each latent with its indicators internally as well as the relationship between latent were greater or equal to the preferred loading factor $\geq 0.05$ requirements of acceptability. All construct is valid.

\section{Figur 3.}

Factor Loading

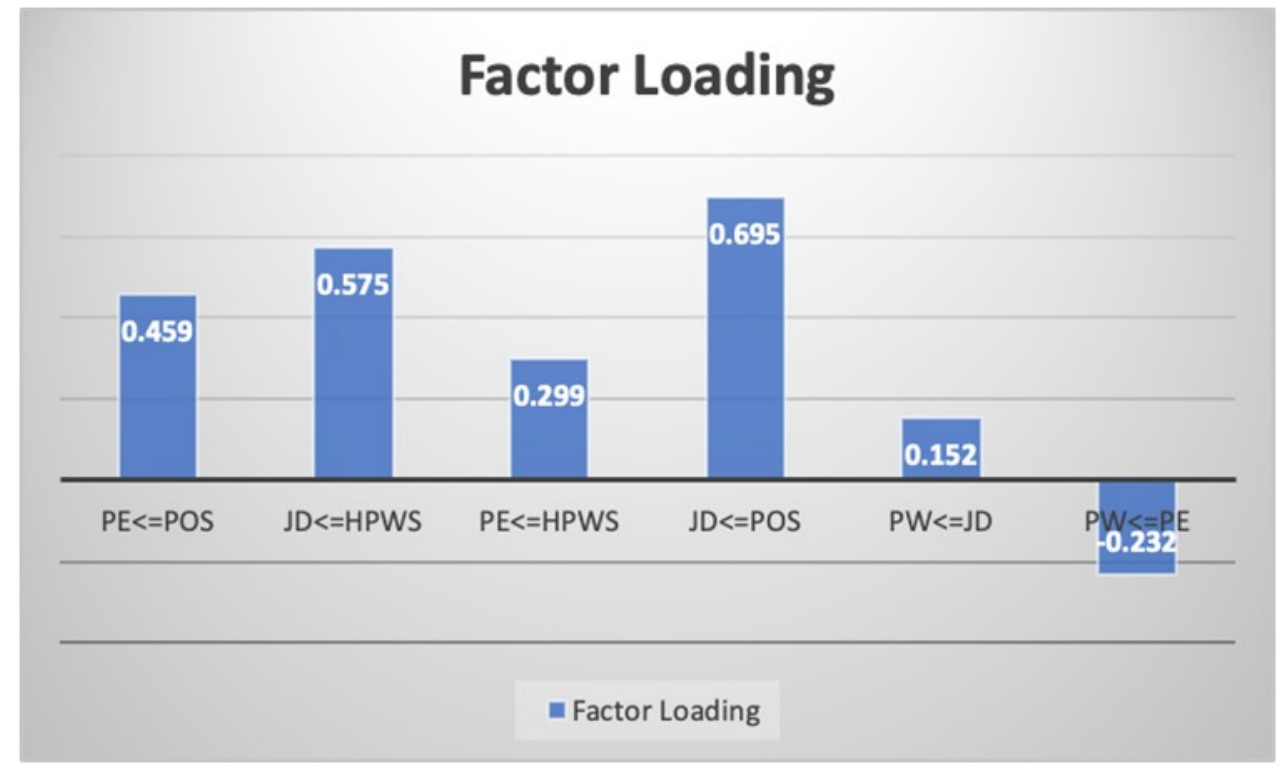

Construct has good reliability, if: (i) the value of Construct reliability $(\mathrm{CR})>0.7$; and (ii) the average (average) variance extracted (VE) or $\mathrm{AVE} \geq 0.5$. AVE value of all indicator elements was greater or equal to the preferred $\mathrm{AVE} \geq 0.50$ requirements of acceptability. All construct is reliable.

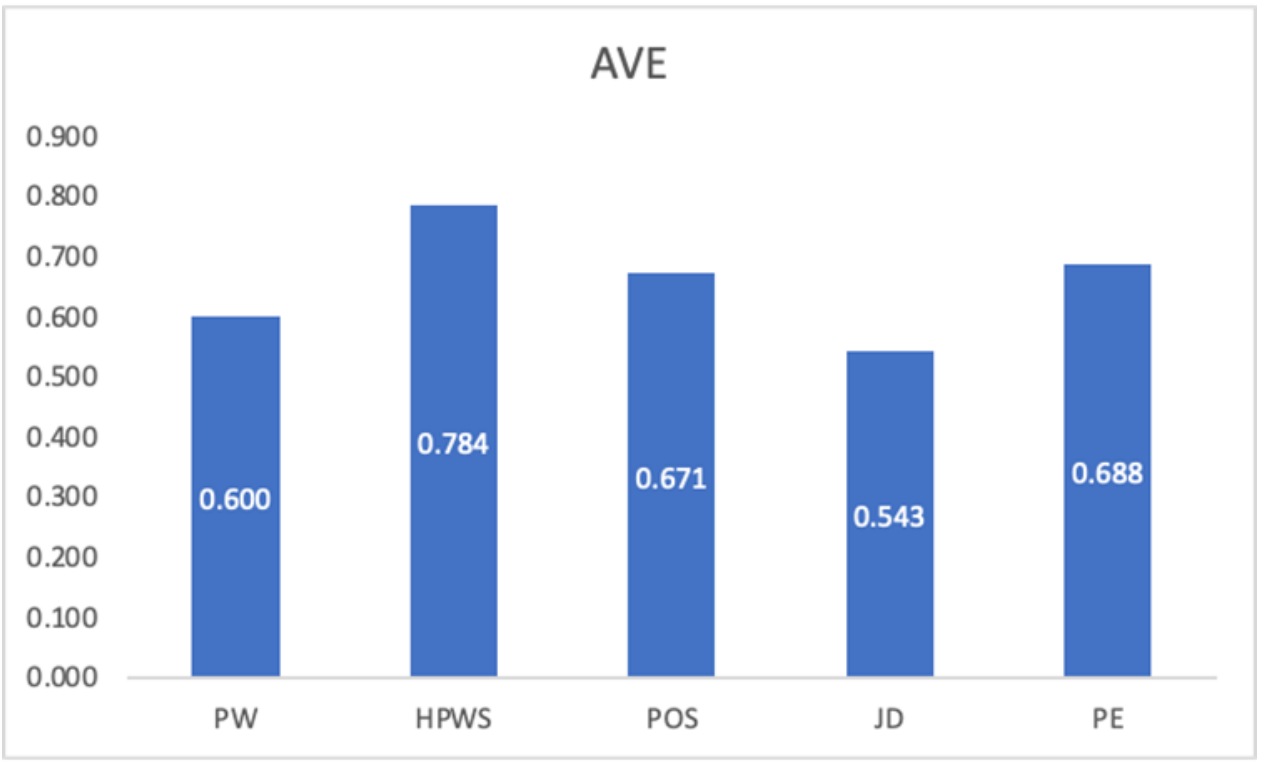

The relationship between perceived organizational support (POS) and perceived workload (PW) is mediated by psychological empowerment (PE).

Hypothesis 1 reads: There will be a negative relationship between perceived organizational support (POS) and perceived workload (PW) is mediated by psychological empowerment (PE). 
Based on the research results, it is proven that the relationship between POS and PW through PE is -9.721804, which means that the $t$-Value or CR score is $-9.721804 \geq 1.967$. Significance $(P) \leq 0.05$, this means that $\mathrm{H} 0$ is rejected, Ha is accepted, which means POS has a negative and significant effect on PE. The mean of this research hypothesis 1 is proven through this research.

The findings of Allen, Armstrong, Reid \& Riemenschneider (2008) empirical research show that 23 agencies and found increased workload in dissatisfaction and demotivation. The result was not significant, therefore the expected high perceived workload to have a strongly negative relationship with POS was supported. This means that the results of this study support Allen et al (2008).

The relationship between perceived organizational support (POS) and perceived workload (PW) are positively related is mediated by job demand (JD).

Hypothesis 2 reads: The relationship between perceived organizational support (POS) and perceived workload (PW) are positively related is mediated by job demand (JD).

Based on the research results, it is proven that the POS relationship with PW through JD is 7,616943. which mean score t-Value or CR of 7,616943. $\geq 1,967$. Significance $(\mathrm{P}) \leq 0.05$, this means that H0 is rejected, Ha is accepted, which means POS has a positive and significant effect on PE. The mean of this research hypothesis 2 is proven through this research.

The results of this study support the research results of Ghislieri, Gatti, Molino, and Cortese (2016) which state that work demands were possible predictors of WFC, consistent with previous research (O'Driscoll et al. 2006, van Veldhoven \& Beijer 2012). Emotional dissonance was significant in work-to-family interactions: the effort required to display emotions at work different from those felt could have spillover effects in other life domains, supporting findings from other careers (Emanuel et al. 2014). However, the results of this study contradict the results of research (Gurbuz et al. 2012) who found that WFC was negatively correlated with POS.

The relationship between perceived - HPWS (HPWS) and perceived workload (PW) is mediated by psychological empowerment (PE).

Hypothesis 3 reads: The relationship between perceived - HPWS (HPWS) and perceived workload (PW) is mediated by psychological empowerment (PE).

Based on the results of the study, it was proven that the relationship between HPWS and PW through PE was 7.177472. which means the $t$-value or $C R$ is -7.177472 . $\geq 1,967$. The significance $(P) \leq 0.05$, this means $\mathrm{H} 0$ is accepted and $\mathrm{Ha}$ is rejected, which means that HPWS has a negative and significant effect on PW mediated by PE. It means that hypothesis 3 is not proven through this research.

The results of this study are in line with the findings of Rani, Rahman \& Yusak (2021) empirical research show that a predicted that perceived - HPWS and service employees' performance in the automotive retail industry is mediated by psychological empowerment. The research takes 4 steps to analyze the mediating effect. Firstly, the perceived HPWS (independent variable) has to directly affect service employee performance (dependent variable). Next, to test the perceived HPWS have to directly influence the psychological empowerment (proposed mediator) and the proposed mediator has to directly influence the dependent variable. Finally, comparison of the significant values when the variables are added to the regression analysis. The results will be fully mediated when the significant relationship between independent variables and dependent variables must become insignificant after incorporating the mediator into the regression analysis.

The relationship between perceived - HPWS (HPWS) and perceived workload (PW) is negative mediated by job demand (JD).

Hypothesis 4 reads: The relationship between perceived - HPWS (HPWS) and perceived workload (PW) is negative mediated by job demand (JD).

Based on the research results, the relationship between HPWS and PW through JD is 7.479422 which mean t-value or CR score of $7.479422 \geq 1.967$. Significance $(P) \leq 0.05$, this means that $\mathrm{H} 0$ is accepted, Ha is rejected, which means HPWS has a positive and significant effect to PW mediated by JD. The mean of hypothesis 4 was not proven through this study.

However, the results of this study are in line with the results of empirical research by Kloutsiniotis \& Mihail (2020) proposed that employees' perceptions of HPWS will be positively associated with job demands (work overload and worked family conflict) and job resources, respectively. The findings showed that the relationship between HPWS and both job demands is negative and significant. 
Based on the research results and related to the formulation of the problem, it can be concluded that:

1 The results showed that POS has a negative and significant effect to PW mediated by PE. This means that hypothesis 1 is proven. Hypothesis 1 reads: There will be a negative relationship between perceived organizational support (POS) and perceived workload (PW) is mediated by psychological empowerment (PE).

2 The results showed that POS had a positive and significant effect on PW with JD mediation. This means that hypothesis 2 is proven. Hypothesis 2 reads: The relationship between perceived organizational support (POS) and perceived workload (PW) are positively related is mediated by job demand (JD).

3 The results showed that HPWS has a negative and significant effect to PW mediated by PE. This means that hypothesis 3 is not proven. Hypothesis 3 reads: The relationship between perceived - HPWS (HPWS) and perceived workload (PW) is mediated by psychological empowerment (PE).

4 The results showed that HPWS had a positive and significant effect on PW with JD mediation. This means that hypothesis 4 is not proven. Hypothesis 4 reads: The relationship between perceived-HPWS (HPWS) and perceived workload (PW) is negative mediated by job demand (JD).

Based on the research results, the following suggestions can be made:

1 Given that POS is proven to have a negative effect on PW through PE, management should continue to demonstrate its commitment to ongoing essential management that provides support to employees at work. Management support in various forms such financial and non-financial support will ease employees' careers even though they are overloaded.

2 Likewise, HPWS without being mediated by other variables has a negative effect on PW. It means that HPWS has a positive value for employees so that employees do not feel burdened by so much work; management must accommodate the HPWS (system) adequately.

\section{Reference}

Abbasi, S. G., Shabbir, M. S., Abbas, M., \& Tahir, M. S. (2020). HPWS and knowledge sharing behavior: The role of psychological empowerment and organizational identification in public sector banks. Journal of Public Affairs, September. https://doi.org/10.1002/pa.2512

Abubakar, A. M., Foroutan, T., \& Megdadi, K. J. (2019). An integrative review: High-performance work systems, psychological capital and future time perspective. International Journal of Organizational Analysis, 27(4), 1093-1110. https://doi.org/10.1108/IJOA-12-2017-1302

García-Chas, R., Neira-Fontela, E., \& Castro-Casal, C. (2014). High-performance work system and intention to leave: A mediation model. In International Journal of Human Resource Management (Vol. 25, Issue 3, pp. 367-389). Taylor \& Francis. https://doi.org/10.1080/09585192.2013.789441

Ghislieri, C., Gatti, P., Molino, M., \& Cortese, C. G. (2017). Work-family conflict and enrichment in nurses: between job demands, perceived organisational support and work-family backlash. Journal of Nursing Management, 25(1), 65-75. https://doi.org/10.1111/jonm.12442

Kloutsiniotis, P. V., \& Mihail, D. M. (2020). Is it worth it? Linking perceived high-performance work systems and emotional exhaustion: The mediating role of job demands and job resources. European Management Journal, 38(4), 565-579. https://doi.org/10.1016/j.emj.2019.12.012

Kurtessis, J. N., Eisenberger, R., Ford, M. T., Buffardi, L. C., Stewart, K. A., \& Adis, C. S. (2017). Perceived Organizational Support: A Meta-Analytic Evaluation of Organizational Support Theory. Journal of Management, 43(6), 1854-1884. https://doi.org/10.1177/0149206315575554

Liu, F., Chow, I. H. S., Zhu, W., \& Chen, W. (2020). The paradoxical mechanisms of high-performance work systems (HPWSs) on perceived workload: A dual-path mediation model. Human Resource Management Journal, 30(2), 278-292. https://doi.org/10.1111/1748-8583.12277

Mansour, S., \& Tremblay, D. G. (2016). Workload, generic and work-family specific social supports and job stress: Mediating role of work-family and family-work conflict. International Journal of Contemporary Hospitality Management, 28(8), 1778-1804. https://doi.org/10.1108/IJCHM-11-2014-0607

Mat, R., Rafida, N., Rahman, A., Aqilah, N., \& Yusak, M. (2021). The relationship between high performance work system ( HPWS ), psychological empowerment ( PE ) and service employees 'performance ( SEP ): Evidence from automotive retail industry. 11, 1-6. https://doi.org/10.5267/j.msl.2021.1.011

Sadiq, M. (2020). Policing in pandemic: Is perception of workload causing work-family conflict, job dissatisfaction and job stress? Journal of Public Affairs, September. https://doi.org/10.1002/pa.2486

Tang, G., Yu, B., Cooke, F. L., \& Chen, Y. (2017). High-performance work system and employee creativity: The roles of perceived organisational support and devolved management. Personnel Review, 46(7), 1318-1334. https://doi.org/10.1108/PR-09-2016-0235 